\title{
Co-immobilization of Nano-Metal and C. pasteurianum for Dark Fermentation Anaerobic Hydrogen Production
}

\author{
Anongnart Wannapokin, Yu-Tzu Cheng, Sheng-Zhe Wu, Ping-Heng Hsieh, and Chun-Hsiung Hung
}

\begin{abstract}
In the suspension culture, the sharp structure of some nano-metals may destroy the cells and cause metal washout from the system, causing secondary pollution. A novel method of combination of nano-metals addition and immobilized dark fermentation microorganism can overcome this problem. In this study, the co-immobilization approach, nano-metal and the dark-fermented bacteria were incubated together within PVA-boric acid gel granule, could prevent washout of hydrogen producing microorganism as well as the added nano-metals. The results showed when $400 \mathrm{mg} / \mathrm{L}$ nano-metal nickel (NP-Ni) and $400 \mathrm{mg} / \mathrm{L}$ nano-metal iron (NP-Fe) were added within the immobilized cell, both the maximum $\mathrm{H}_{2}$ production yield (HPY) and $\mathrm{H}_{2}$ production rate (HPR) were improved to be $1.28 \mathrm{~mol} \mathrm{H}_{2} / \mathrm{mol}$ glucose, $3.13 \mathrm{H}_{2}$ $\mathrm{L} / \mathrm{L} /$ day and $1.19 \mathrm{~mol} \mathrm{H}_{2} / \mathrm{mol}$ glucose, $1.90 \mathrm{H}_{2} \mathrm{~L} / \mathrm{L} / \mathrm{day}$, respectively. The method is expected not only to allow microorganisms to have higher environmental tolerance but also increase hydrogen production.
\end{abstract}

Index Terms - Hydrogen, dark fermentation, immobilization, nano-metal.

\section{INTRODUCTION}

Nowadays, energy is indispensable in human life. The main source of energy is still from non-renewable energy sources, which has brought about environmental problems such as the greenhouse effect and abnormal climate. If we do not change the current habits and perceptions of using energy, the damage of the environment will become a catastrophic result, and it will result in the inability to recover. Therefore, the selection of energy has become a very important issue at present. Among the many alternative green renewable energy sources, the one energy source that receives special attention for responding to these requirements is hydrogen. Hydrogen has the most prospects and potential. What is the value of hydrogen with such high potential, because hydrogen only produces water after it is completely burned, it has clean and non-polluting properties to the environment, and it can provide a higher heat of combustion.

Dark fermentation anaerobic hydrogen production can adapt to whole weather conditions and not require light sources. It can use a variety of carbon sources to produce

Manuscript received March 5, 2019; revised August 12, 2019. This work was financially supported by the R.O.C Ministry of Science and Technology (MOST) (MOST 107-2221-E005-001-MY3).

The authors are with the Department of Environmental Engineering, National Chung-Hsing University, Taiwan (e-mail Anongnartwannapokin@gmail.com, wibbly520@gmail.com, james562443@gmail.com, stringbird@gmail.com, badger@nchu.edu.tw). valuable metabolic by-products such as acetic acid, butyric acid and alcohols [1]. However, due to the low efficiency of dark fermentation bio-hydrogen production, several reports have tried to find ways to improve hydrogen production efficiency, so that hydrogen production systems can achieve optimal conditions [2].

In most of the bio-hydrogen production studies which are often used in the form of suspension culture. However, microorganisms are often washed out in continuous flow systems, resulting in unstable operating conditions and reduced hydrogen production [3]. Therefore, many studies use immobilization techniques to immobilize microbial cells to prevent loss of biomass, resulting in reduced microbial cell density and hydrogen production [4]. Immobilized microbial cells have the following advantages: bio-hydrogen production yield can be increased, it can survive under difficult conditions, increase substrate conversion rate, increased the operational ability at higher organic loading rates and shorter residence times, separation and filtration can be simplified, reduced processing costs, make microorganisms reusable, minimize contamination from microorganisms and protect microorganisms from shear stresses caused by agitation [4]. Hydrogen production is associated with cell growth, and high cell density should be a prerequisite for high hydrogen production. Immobilized cells can increase cell density in bioreactors resulting in increased hydrogen production [5].

Nanotechnology has excellent performance in many applications such as catalysis, optics, and medicine. In recent years. Application of nano-metal materials to a biological system is becoming popularization as it has unique physical and chemical properties. Currently, in order to overcome the limitation of low-hydrogen production by dark fermentation, nanoparticle (NP) like nano-metal or nano-metal oxides had been demonstrated to be able to enhance intracellular electron transfer and promote $[\mathrm{NiFe}]$-hydrogenase and $[\mathrm{FeFe}]$-hydrogenase activity and increase hydrogen production [6], [7]. In addition, many researchers have shown that the smaller nanoparticle size is better than the bigger one about the hydrogen production rate [8].

At present, most of the studies on adding nano-metal to dark fermentation bio-hydrogen production are based on suspension culture. In contrast, during suspension culture, the sharp structure of some nano-metals may destroy the cells and may cause the metal to wash out from the system, causing secondary pollution [9]. Therefore, this study attempts to co-immobilized nano-metals and $C$. pasteurianum for dark fermentation anaerobic hydrogen production, and observe the hydrogen production state of the anaerobic fermentation microorganisms. 


\section{MATERIAL AND METHOD}

\section{A. Microorganism and Culture Medium}

The hydrogen production bacteria (HPB), Clostridium pasteurianum $\mathrm{CH} 5$, used in this study was isolated from a sugar-containing wastewater treatment system. Each month, $10 \mathrm{~mL}$ of pre-incubated bacterial liquid was transferred to a serum bottle containing $90 \mathrm{~mL}$ of fresh PYG matrix (German Species \& Bacterial Preservation Center, Deutsche Sammlung von Mikroorganismen und Zellkulturen, DSMZ), and sealed the $125 \mathrm{~mL}$ serum bottle after replaced the headspace with argon gas to maintain the anaerobic environment. The PYG medium component contains 0.04 $\mathrm{mg} / \mathrm{L}$ of $\mathrm{K}_{2} \mathrm{HPO}_{4}+\mathrm{KH}_{2} \mathrm{PO}_{4}, 0.0008 \mathrm{~g} / \mathrm{L}$ of $\mathrm{CaCl}_{2}, 0.08 \mathrm{~g} / \mathrm{L}$ of $\mathrm{NaCl}, 0.0192 \mathrm{~g} / \mathrm{L}$ of $\mathrm{MgSO}_{4} \cdot 7 \mathrm{H}_{2} \mathrm{O}, 0.04 \mathrm{~g} / \mathrm{L}$ of $\mathrm{NaHCO}_{3}$, $5 \mathrm{~g} / \mathrm{L}$ of peptone, $5 \mathrm{~g} / \mathrm{L}$ of tryptone, $10 \mathrm{~g} / \mathrm{L}$ of yeast extract, $1.1 \mathrm{mg} / \mathrm{L}$ of $\mathrm{FeSO}_{4} \cdot 7 \mathrm{H}_{2} \mathrm{O}$ and $5 \mathrm{~g} / \mathrm{L}$ of glucose, and the initial $\mathrm{pH}$ of the medium was adjusted to 7 [10].

\section{B. Preparation of $\mathrm{Fe}(\mathrm{NP}-\mathrm{Fe})$ and $\mathrm{Ni}(\mathrm{NP}-\mathrm{Ni})$ Nanoparticles}

Magnetic hematite nanoparticles, with a nominal size of $50-100 \mathrm{~nm}$ and $97 \%$ trace metal basis, were provided by SIGMA-Aldrich Corp. (St. Louis, MO, U.S.A.). Magnetic nickel with a nominal size of $30-50 \mathrm{~nm}$ and $97 \%$ trace metal basis, were provided by UniRegion Bio-Tech Corp. (Taiwan, R.O.C.).

\section{Immobilization Method}

The immobilization method selected for the experiment was the entrapment method which was carried out by referring to Wang et al. [11]. First, $3.5 \mathrm{~g} / \mathrm{L}$ of Alginate and $0.5 \mathrm{~g} / \mathrm{L}$ of $\kappa$-carrageenan were mixed with $30 \mathrm{~mL}$ of deionized water in the serum and sterilized in an autoclave $\left(121^{\circ} \mathrm{C}\right)$. After sterilization, adding $7.0 \mathrm{~g} / \mathrm{L}$ of polyvinyl alcohol with $10 \mathrm{ml}$ of sterile water in the serum at laminar flow, and placed in an oven at $80^{\circ} \mathrm{C}$ two hours, after the heating, shaking it appropriate time to evenly mix, then add $\mathrm{CH} 5$ bacteria solution $(\mathrm{OD}=1,50 \mathrm{~mL}$ concentrated to $10 \mathrm{~mL}$ ) and nano-metal $(\mathrm{Fe}, \mathrm{Ni})$ at the laminar flow. Finally, extract $10 \mathrm{~mL}$ of all mixed colloids with a syringe, and add $\mathrm{CaCl}_{2}$ of $1.8 \%(\mathrm{w} / \mathrm{v} \%)$ and $\mathrm{H}_{3} \mathrm{BO}_{3}$ of $2 \%(\mathrm{w} / \mathrm{v} \%)$ of the cross-linking agent, and placed in a refrigerator at $4{ }^{\circ} \mathrm{C}$ for $18-24$ hours, to form diameter 3-4 mm of boric acid gel particles, and washed with sterile water several times, then stored in a refrigerator at $4^{\circ} \mathrm{C}$ overnight.

\section{Analysis of Hydrogen Production}

The volume of the headspace gas of the batch bottle after the end of the final experiment was extracted with a gas volume of $0.5 \mathrm{~mL}$ gas volume, and the gas chromatography-thermal conductivity detector (GC-TCD) was used to analyze the composition of the inorganic gas generated in the batch bottle. In the experiment, the argon gas (Ar) is filled in the headspace of the serum. Therefore, the carrier gas in the GC-TCD cannot use argon gas but helium gas $(\mathrm{He})$. The gas chromatograph used in the study was Agilent GC-7890A, the detector was a thermal conductive detector, the tube was 60/80 Carboxen-1000, the initial temperature was $35^{\circ} \mathrm{C}$, and the temperature was raised to $20^{\circ} \mathrm{C} / \mathrm{min}$ until $225^{\circ} \mathrm{C}$, the carrier gas is $\mathrm{He}$, the flow rate is $30 \mathrm{~mL} / \mathrm{min}$, the temperature of the injector is $100^{\circ} \mathrm{C}$. The calibration curve is obtained by using a standard mixture gas $\left(40 \%\right.$ of $\mathrm{H}_{2}, 30 \%$ of $\mathrm{CO}_{2}$, and $30 \%$ of $\mathrm{CH}_{4}$ ) in different volumes $(0.4,0.5,0.6,0.8$ and $1.0 \mathrm{~mL})$ after analysis by gas chromatography. The signal area and gas volume are plotted as a calibration curve.

\section{RESULTS AND DISCUSSION}

\section{A. Comparison of Immobilized and Suspended Microorganism on Hydrogen Production by Dark Fermentation}

After 96 hours of incubation, the cumulative biogas production and hydrogen production of immobilized $\mathrm{CH} 5$ (control), the $\mathrm{CH} 5$ with nano-metals co-immobilized, and the suspended CH5 are shown in Fig. 1 and Fig. 2.

Results showed that the cumulative gas production of $\mathrm{CH} 5$ after gel immobilization was better than the suspended ones, regardless of whether the nano-metals was added or not. As shown in Fig. 2, the hydrogen production of immobilized CH5 is also significantly better as well, which can increase hydrogen production to about $16 \%$. The amount of carbon dioxide production was less than that in suspension form. In another research, when the retention time is controlled at 24 hours, the hydrogen production rate of the immobilized anaerobic sludge and suspension state is 2.10 and 0.99 mol $\mathrm{H}_{2} /$ mol respectively. This is in agreement with what had been reported that the immobilized approach performed better [12]. The research of $\mathrm{Wu}$ et al. indicated that using sucrose to be carbon source, the result of hydrogen production rate about immobilized other strain of Clostridium sp. and suspension state is 21.3 and $6.8 \mathrm{mmol} / \mathrm{L} / \mathrm{h}$ respectively, that is three times more than suspension state under batch experiment of immobilization and suspension state by fermentation [13]. These research are consistent with the results of our research, it can be proved that the immobilized Clostridium sp. can indeed increase hydrogen production.

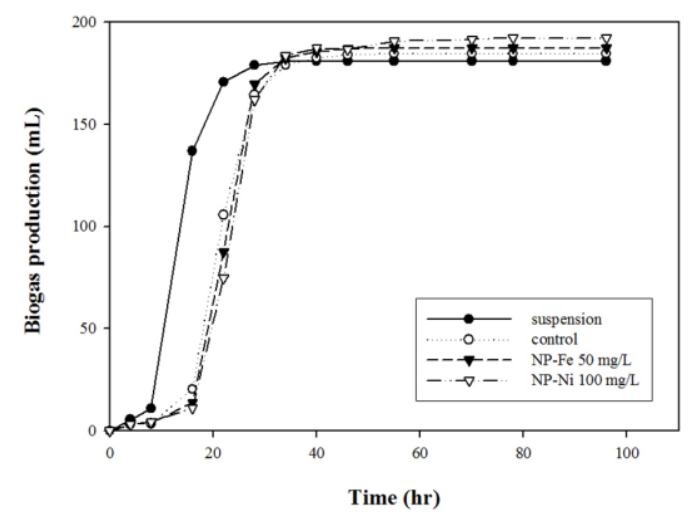

Fig. 1. Accumulative biogas production of immobilized $\mathrm{CH} 5$ and suspended CH5.

However, in the case of cell immobilization, there is no significant difference in accumulative biogas production and hydrogen production with or without nano-metal addition. Therefore, it is questionable that co-immobilization of $\mathrm{CH} 5$ and nano-metal did improve hydrogen production as previously proposed. Hsieh et al. indicated that nano-metal 
improved electron transfer after directly contacting the microbial cell membrane, thereby increasing the electron transfer rate between hydrogenase and ferredoxin, and improving hydrogen production [9]. Therefore, the subsequent processing conditions for the preparation of the granules will be adjusted in the next step to find a suitable preparation method and establish an optimum granule preparation operating condition.

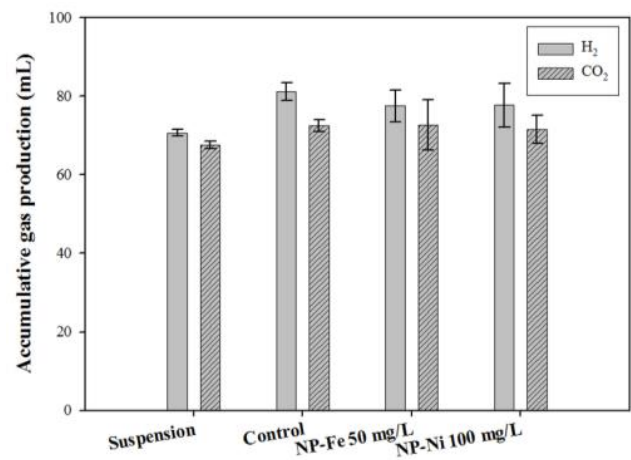

Fig. 2. Accumulative gas composition of immobilized $\mathrm{CH} 5$ and suspended CH5.

\section{B. Establishing Optimal Granule Preparation Conditions}

The purpose of this study is to establish a better granule preparation procedure for hydrogen production. Difference between gel mixed with nano-metal before adding microorganisms ( $\mathrm{CH} 5$ is not directly contacted with the nano-metal) and pre-incubating nano-metal with $\mathrm{CH} 5$ before adding gel (CH5 contacted with the nano-metal directly) was examined to study the effect of stimulation. NP-Ni was selected as the testing metal at different concentrations of 0 (control), 100, 200, 300 and $400 \mathrm{mg} / \mathrm{L}$.

\section{1) Gel mixed with nano-metal before adding microorganisms}

After 96 hours of culture, there is little difference in the group of NP-Ni and control, but significantly different was observed when adding $200 \mathrm{mg} / \mathrm{L}$ NP-Ni. Its cumulative biogas production improved up to $28 \%$ more than the control group (Fig. 3). But it can not improve hydrogen production (Fig. 4). Moreover, the standard deviation in the batch of three repeat groups is rather large and unstable. Therefore, it is speculated that the granules prepared by this method cannot effectively contact with $\mathrm{CH} 5$ and nano-metal.

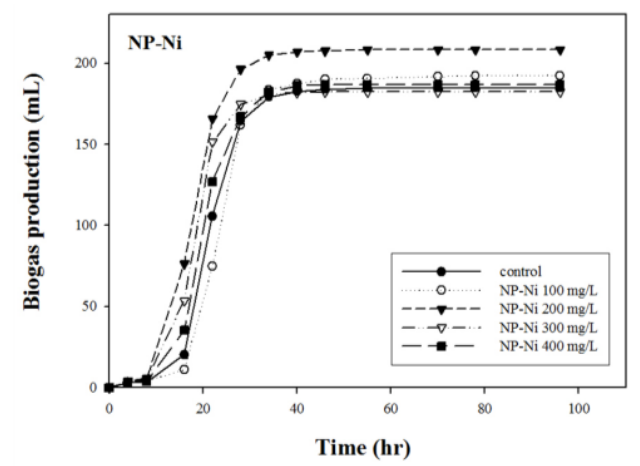

Fig. 3. Accumulative biogas production of gel mixed with nano-metal before adding $\mathrm{CH} 5$.

\section{2) Pre-incubating CH5 with Nano-metal before adding gel}

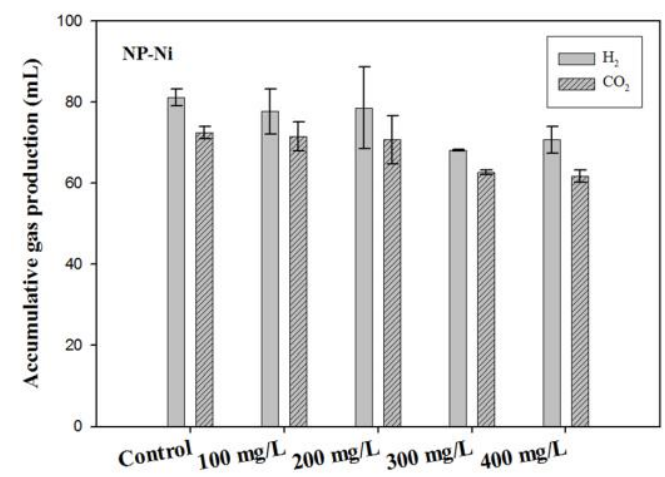

Fig. 4. Accumulative gas composition of gel mixed with nano-metal before adding CH5.

After 145 hours of incubation, it was found that accumulative biogas production of adding NP-Ni is better than the control group for every tested concentration. Adding 100-400 mg/L NP-Ni can improve 13-32\% of accumulative biogas production more than the control group (Fig. 5). On the cumulative hydrogen production, 36-51\% improving were observed than the control group (Fig. 6). Moreover, the standard deviation in the batch of three repeat groups is small and stable. It is speculated that pre-incubated $\mathrm{CH} 5$ with nano-metal before making gel granules is the right approach for this proposal as illustrated in Fig. 7.

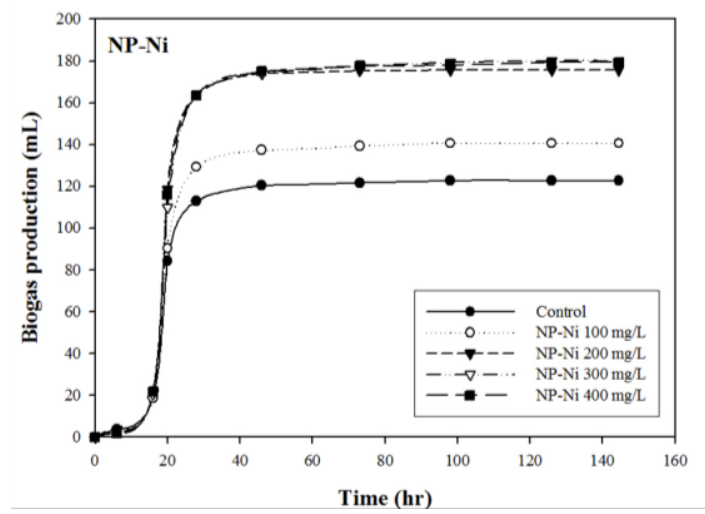

Fig. 5. Accumulative biogas production of nano-metal mixed with $\mathrm{CH} 5$ before adding gel.

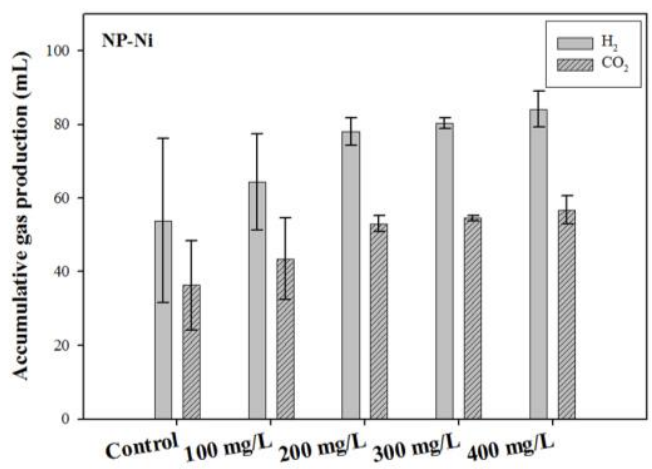

Fig. 6. Accumulative gas composition of nano-metal mixed with $\mathrm{CH} 5$ before adding gel.

\section{Performance of Metal-Microorganism Pre-incubated Method under Different Concentrations of Nano-Metal}

\section{1) NP-Ni as added metal}

After establishing the metal-microorganism pre-incubated method for granular preparation, all the following experiment were performed with this approach. The cumulative gas 
production was improved to $13 \%, 30 \%, 32 \%$, and $32 \%$ respectively when adding 100, 200, 300 and $400 \mathrm{mg} / \mathrm{L} \mathrm{NP}-\mathrm{Ni}$, the maximum cumulative biogas production is $180.0 \mathrm{~mL}$ when adding $300 \mathrm{mg} / \mathrm{L}$ NP-Ni. And the cumulative hydrogen production was improved $36 \%, 47 \%, 49 \%$, and $51 \%$ respectively, and the maximum cumulative hydrogen production is $84.1 \mathrm{~mL}$ when adding $400 \mathrm{mg} / \mathrm{L} \mathrm{NP}-\mathrm{Ni}$. It can be seen from the above that as long as the concentration of nano-metal Ni higher than $200 \mathrm{mg} / \mathrm{L}$, hydrogen production will be improved as shown in Fig. 8 and Fig. 9. However, according to the study of Hsieh, when adding a higher concentration of NP-Ni into suspended dark fermentation hydrogen production system, will lead to a decrease in cumulative biogas production and hydrogen production [9]. In this study, co-immobilized with NP-Ni and $\mathrm{CH} 5$ in the granule did not cause negative hydrogen production under high concentration of NP-Ni addition. It was speculated that this proposed granular preparation might reduce the toxicity of high concentration of nano-metal addition.
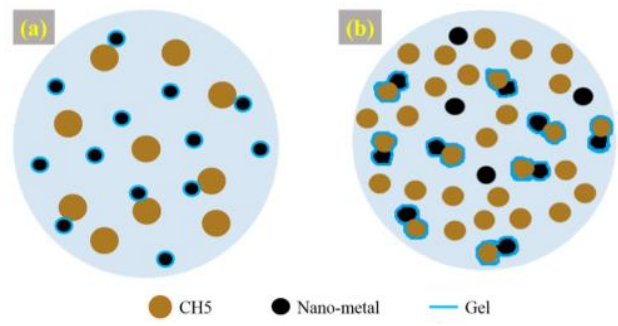

Fig. 7. Comparison of differences in operating conditions of granules preparation (a) gel mixed with nano-metal before adding $\mathrm{CH} 5$ and (b) nano-metal mixed with $\mathrm{CH} 5$ before adding gel.

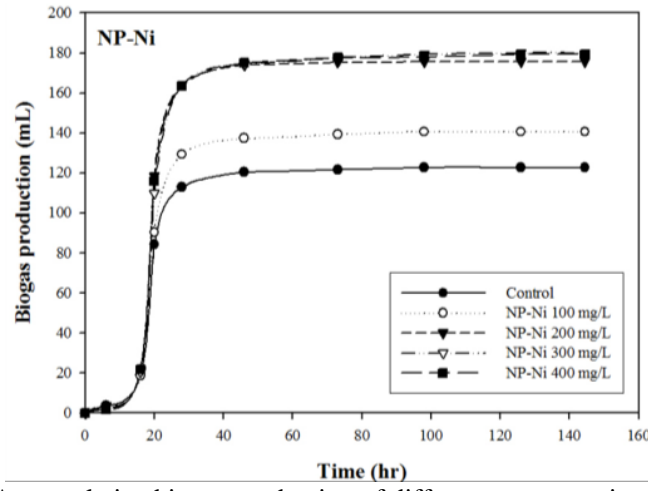

Fig. 8. Accumulative biogas production of different concentration of NP-Ni.

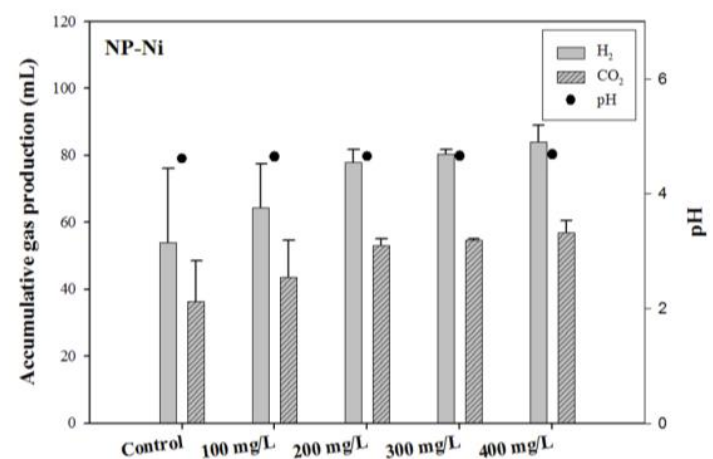

Fig. 9. Accumulative gas composition of different concentration of NP-Ni.

When the addition of NP-Ni concentration is 0 (control), $100,200,300$ and $400 \mathrm{mg} / \mathrm{L}$, the value of hydrogen production yield was $0.62,0.97,1.18,1.22$ and $1.28 \mathrm{~mol}$ $\mathrm{H}_{2} /$ mol glucose respectively. It showed that co-immobilized with $\mathrm{CH} 5$ and NP-Ni can also improve hydrogen production yield, and the maximum value is $1.28 \mathrm{~mol} \mathrm{H}_{2} / \mathrm{mol}$ glucose when adding $400 \mathrm{mg} / \mathrm{L} \mathrm{NP-Ni}$. The hydrogen production rate from low to high concentration of NP-Ni addition is 2.20 , 2.87, 2.98 and $3.13 \mathrm{H}_{2} \mathrm{~L} / \mathrm{L} /$ day respectively. It increased when the concentration of NP-Ni was higher. All of these production rates were better than the control group $\left(1.88 \mathrm{H}_{2}\right.$ $\mathrm{L} / \mathrm{L} /$ day). In terms of gas composition, it does not change under different concentration of NP-Ni addition, and the average percentage of hydrogen gas is greater than $44 \%$.

2) NP-Fe as added metal

The cumulative biogas production was improved up to $15 \%, 9 \%, 15 \%$, and $16 \%$ respectively when 50, 100, 200 and $400 \mathrm{mg} / \mathrm{L}$ NP-Fe were added. Maximum cumulative biogas production was $179.0 \mathrm{~mL}$ when adding $400 \mathrm{mg} / \mathrm{L} \mathrm{NP}-\mathrm{Fe}$. Cumulative hydrogen production was improved up to $22 \%$, $18 \%, 27 \%$, and $27 \%$ respectively, and the maximum cumulative hydrogen production was $74.2 \mathrm{~mL}$ when adding $400 \mathrm{mg} / \mathrm{L} \mathrm{NP}-\mathrm{Fe}$. It can be seen from the results that as long as $50 \mathrm{mg} / \mathrm{L} \mathrm{NP}-\mathrm{Fe}$ or more were added, improved hydrogen production was observed as showing in Fig. 10 and Fig. 11.

However, according to the study of Hsieh et al., when a higher concentration of NP-Fe was added into a suspended growth of dark fermentation hydrogen production system, accumulative biogas production and hydrogen production decreased significantly [9]. This inhibition was not observed in this study under high concentration of NP-Fe addition. This is similar to the previous result on NP-Ni as this proposed granular preparation indeed could reduce the toxicity of higher concentration of nano-metal addition.

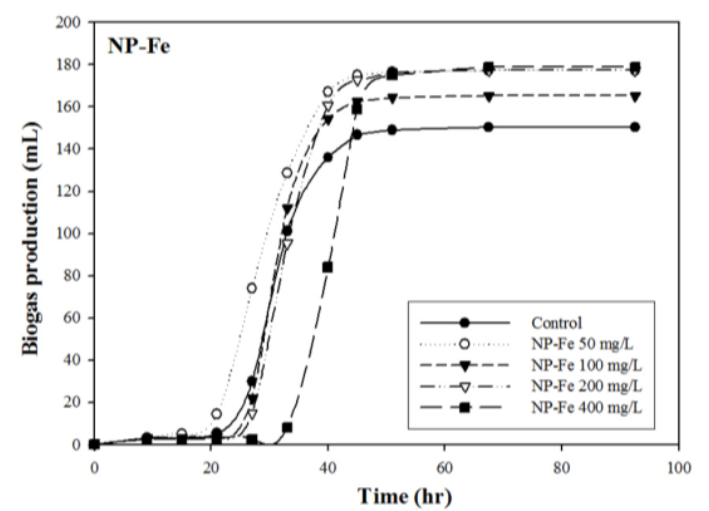

Fig. 10. Accumulative biogas production of different concentration of NP-Fe.

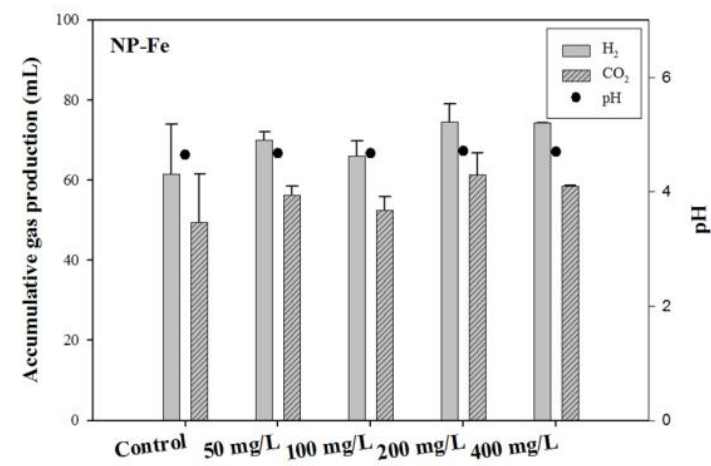

Fig. 11. Accumulative gas composition of different concentration of NP-Fe.

When the addition of NP-Fe concentration is 0 (control), $50,100,200$ and $400 \mathrm{mg} / \mathrm{L}$, the value of hydrogen production 
yield was $0.86,1.09,1.05,1.19$ and $1.19 \mathrm{~mol} \mathrm{H}_{2} / \mathrm{mol}$ glucose respectively. It showed that added NP-Fe can improve hydrogen production yield, and the maximum value is 1.19 mol $\mathrm{H}_{2} / \mathrm{mol}$ glucose when adding 200 and $400 \mathrm{mg} / \mathrm{L} \mathrm{NP}-\mathrm{Fe}$. Hydrogen production rate from low to high concentration NP-Fe addition is $1.53,1.46,1.70$ and $1.90 \mathrm{H}_{2} \mathrm{~L} / \mathrm{L} /$ day respectively. All of these production rates were better than the control (1.29 $\mathrm{H}_{2} \mathrm{~L} / \mathrm{L} /$ day). Ratios of gas composition in a different concentration of NP-Fe addition were about the same and the average of hydrogen gas percentage is about $39 \%$.

\section{CONCLUSION}

The purpose of this study is to test the feasibility of co-immobilization of nano-metal and $C$. pasteurianum $\mathrm{CH} 5$ for dark fermentation anaerobic hydrogen production. Different methods of granules preparation were tested. Accumulative biogas production and the cumulative hydrogen production in immobilized form were all better than in the suspended form, and the immobilized $\mathrm{CH} 5$ could increase a $16 \%$ of hydrogen production. The better-immobilized protocol could be achieved when nano-metal and microorganisms were incubated together before being made to gel granules. The maximum cumulative biogas production of nano-metal nickel (NP-Ni) was 32\% higher than the control group, and the cumulative hydrogen production was $51 \%$ higher than the control. The maximum cumulative gas production yield of nano-metal iron (NP-Fe) increased by $16 \%$ compared to the control group, and the cumulative hydrogen production increased by $27 \%$ compared with the control group. Overall, this co-immobilization approach, nano-metal and the dark-fermented bacteria were incubated together within PVA-boric acid gel granule, could benefit the hydrogen production and prevent washout of hydrogen producing microorganisms, which shows great potential in application of co-immobilization of $\mathrm{CH} 5$ and nano-metal.

\section{CONFLICT OF INTEREST}

The authors declare no conflict of interest.

\section{AUTHOR CONTRIBUTIONS}

Anongnart Wannapokin, Yu-Tzu Cheng and Sheng-Zhe $\mathrm{Wu}$ concuted the research, analyzed the data and wrote the paper. Ping-Heng Hsieh, and Chun-Hsiung Hung guidelines and instructive.

\section{ACKNOWLEDGMENT}

In this study is supported by the R.O.C Ministry of Science and Technology (MOST) (MOST 107-2221-E005-001-MY3). I wish to thank the Professor Dr. Hung, Chun-Hsiun and the environmental biotechnology laboratory(Lab 615), which is in the National Chung-Hsing University (NCHU) at Taiwan, support of this project.

\section{REFERENCES}

[1] R. Łukajtis, I. Hołowacz, K. Kucharska, M. Glinka, P. Rybarczyk, A. Przyjazny, and M. Kamiński, "Hydrogen production from biomass using dark fermentation," Renewable and Sustainable Energy Reviews, pp. 665-694, June 2018.

[2] Y.-K. Oh, S. M. Raj, G. Y. Jung, and S. Park, "Current status of the metabolic engineering of microorganisms for biohydrogen production," Bioresource Technology, vol. 102, no. 18, pp. 8357-8367, April 2011.

[3] V. Ivanova, P. Gencheva, and J. Hristov, "Application in the ethanol fermentation of immobilized yeast cells in matrix of alginate/magnetic nanoparticles, on chitosan-magnetite microparticles and cellulose-coated magnetic nanoparticles," International Review of Chemical Engineering, vol. 3, no. 2, March 2011.

[4] P. T. Sekoai, A. A. Awosusi, K. O. Yoro, M. Singo, O. Oloye, A. O. Ayeni, M. Bodunrin, and M. O. Daramola, "Microbial cell immobilization in biohydrogen production: a short overview," Critical Reviews in Biotechnology, vol. 38, no. 2, pp. 157-171, April 2017.

[5] J. Han, D. Lee, J. Cho, J. Cho, J. Lee, and S. Kim, "Hydrogen production from biodiesel byproduct by immobilized Enterobacter aerogenes," Bioprocess and Biosystems Engineering, vol. 35, no. 1-2, pp. 151-157, September 2011.

[6] S. K. S. Patel, J.-K. Lee, and V. C. Kalia, "Nanoparticles in Biological Hydrogen Production: An Overview," Indian Journal of Microbiology, vol. 58, no. 1, pp. 8-18, September 2017.

[7] A. Gadhe, S. S. Sonawane, and M. N. Varma, "Enhancement effect of hematite and nickel nanoparticles on biohydrogen production from dairy wastewater," International Journal of Hydrogen Energy, vol. 40, no. 13, pp. 4502-4511, April 2015.

[8] Y. Zhang and J. Shen, "Enhancement effect of gold nanoparticles on biohydrogen production from artificial wastewater," International Journal of Hydrogen Energy, vol. 32, no. 1, pp. 17-23, January 2007.

[9] P.-H. Hsieh, Y.-C. Lai, K.-Y. Chen, and C.-H. Hung, "Explore the possible effect of $\mathrm{TiO}_{2}$ and magnetic hematite nanoparticle addition on biohydrogen production by Clostridium pasteurianum based on gene expression measurements," International Journal of Hydrogen Energy, vol. 41, no. 46, pp. 21685-21691, August 2016.

[10] DSMZ. (2008). PYG MEDIUM (B). [Online]. Available: http://www.dsmz.de/microorganisms/medium/pdf/DSMZ_Medium11 39.pdf

[11] Y.-Z. Wang, Q. Liao, X. Zhu, X. Tian, and C. Zhang, "Characteristics of hydrogen production and substrate consumption of Rhodopseudomonas palustris CQK 01 in an immobilized-cell photobioreactor," Bioresource Technology, vol. 101, no. 11, pp. 4034-4041, February 2010.

[12] B. Kirli and I. K. Kapdan, "Selection of microorganism immobilization particle for dark fermentative biohydrogen production by a repeated batch operation," Renewable Energy, vol. 87, pp. 697-702, March 2016.

[13] K.-J. Wu, J.-S. Chang, and C.-F. Chang, "Biohydrogen production using suspended and immobilized mixed microflora," Journal of the Chinese Institute of Chemical Engineers, vol. 37, no. 6, pp. 545-550, November 2006.

Copyright $\odot 2019$ by the authors. This is an open access article distributed under the Creative Commons Attribution License which permits unrestricted use, distribution, and reproduction in any medium, provided the original work is properly cited ( $\underline{\text { C BY } 4.0)}$.

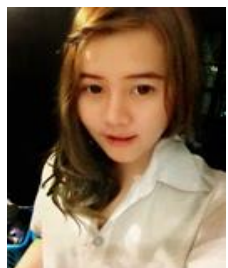

Anongnart Wannapokin was born in Chiang Mai, Thailand on May 24, 1992, who received her bachelor of biotechnology degree in faculty of science with honors from Maejo University (MJU) in 2014 and master degree in biotechnology from Maejo University (MJU) in 2017.

Since 2018, she has been a teaching assistant and a Ph.D. student at the Department of Environmental Engineering in National Chung-Hsing University (NCHU).

Her research interests are environmental engineering and renewable fuels such as biohydrogen production, biogas, biodiesel, bioethanol, biochar, and biomass processing also waste management and biological technique.

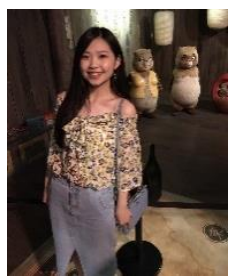

Cheng Yu-Tzu was born in Tainan city, Taiwan on April 3, 1994, who received her bachelor of environmental engineering and science degree with honors from Feng Chia University (FCU) in 2016 and master degree in environmental engineering from National Chung-Hsing University (NCHU) in 2018.

Her research interests are environmental engineering such as biohydrogen biogas, biodiesel, bioethanol, and biomass processing also waste management. 


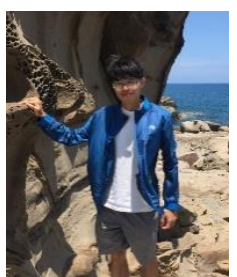

Wu Sheng-Zhe was born in Miaoli county, Taiwan on January 7, 1995, who received his bachelor of environmental engineering degree with honors from Chung Yuan Christian University (CYCU) in 2017.

Since 2017, he has been a master student at the Department of Environmental Engineering in National Chung-Hsing University (NCHU). His research interests are environmental engineering such

as biohydrogen biogas, biodiesel, bioethanol, and biomass processing also waste management.

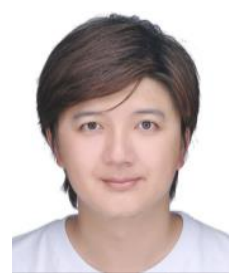

Hsieh Ping-Heng was born in Taitung city, Taiwan on Dec. 25, 1986, who received his bachelor of engineering degree with honors in 2009 and the master degree in environmental science and engineering in 2011 from National Pingtung University of Science and Technology (NPUST), the Ph.D. degree in environmental engineering in 2017 from National Chung-Hsing University (NCHU).

His research interests are environmental engineering and renewable energy such as dark fermentation process, photo fermentation process, microbial fuel cell and reactor tank design.

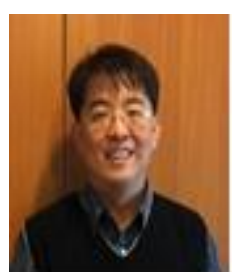

Hung Chun-Hsiun was born in Penghu county, Taiwan on September 2, 1967, who received his bachelor of engineering degree with honors from National Chung-Hsing University (NCHU) in 1990 master degree in civil and environmental engineering in 1994 and Ph.D. degree in civil and environmental engineering in 2000 from University of Wisconsin-Madison (UW)

He was a teaching assistant from 1990 to 1992 in National Chung-Hsing University (NCHU) and a teaching assistant in University of Wisconsin-Madison (UW) from 1993 to 2000. He was an assistant professor from 2001 to 2008, and an associate professor from 2008 to 2013 in National Chung-Hsing University (NCHU). Since 2013, he has been a professor at Department of Environmental Engineering, NCHU.

His research interests are environmental engineering such as the application of molecular biological methods in environmental engineering, anaerobic biohydrogen production, biofuel battery, biological treatment of wastewater (preservation and control), upgrade and optimization of existing wastewater treatment plants and high-efficiency and low-volume wastewater treatment technology development. 